\title{
Sol-Gel Processing and Optical Nonlinearity of Gold Colloid-Doped Silica Glass
}

\author{
Jun MATSUOKA, Ryoichi MIZUTANI, Syoji KANEKO, Hiroyuki NASU, Kanichi KAMIYA, \\ Kohei KADONO*, Toru SAKAGUCHI* and Masaru MIYA* \\ Department of Chemistry for Materials, Faculty of Engineering, Mie University, 1515, Kamihama-cho, Tsu-shi, Mie 514 \\ ${ }^{*}$ Government Industrial Research Institute, Osaka, 1-8-31, Midorigaoka, Ikeda-shi, Osaka 563
}

\author{
金コロイドドープガラスのゾル-ゲル法による調製と光学非線形性 \\ 松岡 純・水谷亮一・兼子祥治・那須弘行・神谷寛一・角野広平*·阪口 亨* ${ }^{*}$ 見矢 勝* \\ 三重大学工学部分子素材工学科, 514 三重県津市上浜町 1515 \\ $*$ 大阪工業技術試験所, 563 大阪府池田市緑ケ丘 1-8-31
}

[Received July 15, 1992; Accepted September 22, 1992]

\begin{abstract}
Au microcrystal-doped glass films with high optical nonlinearity were prepared by the sol-gel method with dip-coating using $\mathrm{NaAuCl}_{4} \cdot 2 \mathrm{H}_{2} \mathrm{O}$ and tetraethyl orthosilicate (TEOS) as starting materials. The glass film with an $\mathrm{Au} / \mathrm{Si}$ atomic ratio of 0.01 was successfully prepared. The nonlinear susceptibility $\chi^{(3)}$ of the film was $7.7 \times 10^{-9} \mathrm{esu}$. Microcrystals with a radius of about $7 \AA$ and of about $30 \AA$ coexisted in the glass film. The nonlinear susceptibility of Au microcrystals itself in the film, $\chi_{\mathrm{m}}{ }^{(3)}$, was $1.0 \times 10^{-7} \mathrm{esu}$ and was two times larger than that observed in Au-doped glasses prepared by the melting method. Subsequent heat treatment of the films at $1000^{\circ} \mathrm{C}$ changed the absorption spectra and decreased $\chi^{(3)}$ by a factor of two. The atomic ratio of $\mathrm{Au} / \mathrm{Si}$ was able to be increased to 0.04 .
\end{abstract}

Key-words : Au-doped glass, Third-order optical nonlinearity, Sol-gel method, Degenerate four-wave mixing, TEM, Crystal radius, Optical absorption, Heat treatment

\section{Introduction}

Metal microcrystals dispersed in transparent matrix have high resonant type third-order optical nonlinearity and thus have a high potential use for all optical logic devices in the future.1)-5) So, optical properties of gold microcrystals embedded in glasses, polymers or aqueous solutions were widely studied nowadays in the linear ${ }^{6)-10)}$ and nonlinear ${ }^{1)-5}$ ) characteristics. In particular, gold microcrystaldoped inorganic glasses ${ }^{1)}$ ) with the microcrystal radius of 10 to $100 \AA$ have been extensively studied because of their high optical nonlinearity, femtosecond order fast response time, convenient operating wavelength near the second harmonic of Nd: YAG laser, and thermal and photochemical stability of the matrix.

In order to use gold-doped glasses as photonic devices, glass should be made as a form of thin film waveguide. So, thin film preparation processes must be developed. Fukumi et al.11),12) used the ion implantation method and obtained a gold microcrystal- doped silica glass with the $\mathrm{Au} / \mathrm{Si}$ atomic ratio of 0.22 and the third order nonlinear optical susceptibility $\chi^{(3)}$ of $1.0 \times 10^{-7}$ esu. Wakabayashi et al. ${ }^{13)}$ used the r.f. sputtering method and obtained an Au-doped glass with the $\mathrm{Au} / \mathrm{Si}$ atomic ratio of 0.03 and $\chi^{(3)}$ of $2.8 \times 10^{-8}$ esu.

Sol-gel method using dip-coating is one of the methods for the preparation of glass films on substrate. Gold-doped silica glasses were successfully prepared with this method by the present authors ${ }^{14)}$ and by Kozuka and Sakka. ${ }^{15)}$ The former authors used sodium tetrachloroaurate $\left(\mathrm{NaAuCl}_{4} \cdot 2 \mathrm{H}_{2} \mathrm{O}\right)$ as a source of $\mathrm{Au}$ and obtained a silica-based glass film with $\mathrm{Au} / \mathrm{Si}$ atomic ratio of 0.01 , and the latter authors used tetrachloroauric acid $\left(\mathrm{HAuCl}_{4} \cdot 4 \mathrm{H}_{2} \mathrm{O}\right)$ and obtained a film with the ratio of about 0.03 . However, effect of preparation condition on the microstructure and optical property of the sol-gel derived Au-doped glasses is not well understood for the present, and $\chi^{(3)}$ of these glasses has not been measured yet.

In this study, we measured the third order nonlinear susceptibility, $\chi^{(3)}$, of gold microcrystal-doped silica glass prepared by sol-gel process for the first time. Microstructure of the glass was investigated by transmitting electron microscopy, and the formation process of gold microcrystals was discussed on the bases of the distribution of crystal radius. Effects of the preparation condition and subsequent heat treatment on $\chi^{(3)}$ were discussed from the viewpoint of microstructure. Further, the effect of the concentration of $\mathrm{NaAuCl}_{4}$ in the precursor silica solution on the glass film formation was investigated.

\section{Experimental procedure}

Au-doped silica glass films were prepared on silica glass plates by dip-coating method. Starting solutions were prepared from tetraethyl orthosilicate $\left(\mathrm{Si}\left(\mathrm{OC}_{2} \mathrm{H}_{5}\right)_{4}\right.$, TEOS), sodium tetrachloroaurate $\left(\mathrm{NaAuCl}_{4} \cdot 2 \mathrm{H}_{2} \mathrm{O}\right)$, ethanol, water and $\mathrm{HCl}$. Molar ratio of TEOS : $\mathrm{NaAuCl}_{4}: \mathrm{EtOH}: \mathrm{H}_{2} \mathrm{O}: \mathrm{HCl}$ was 1 : 
$x: 6: 6: 0.03$, where $x$ corresponds with the $\mathrm{Au} / \mathrm{Si}$ atomic ratio and varied in the range from 0.01 to 0.06 . Most of the experiments were carried out for $x=0.01$ which corresponds to $0.37 \mathrm{vol} \%$ of Au in the resultant $\mathrm{Au} / \mathrm{SiO}_{2}$ composite film. The withdrawal velocity of the silica substrate was fixed at $0.15 \mathrm{~mm} /$ $\mathrm{s}$, resulting in a glass film with about $0.05 \mu \mathrm{m}$ thickness after heat treatment. Heat treatment was carried out in air for $15 \mathrm{~min}$ at different temperatures ranging from $100^{\circ}$ to $600^{\circ} \mathrm{C}$. This dipping/heat treatment procedure was repeated several times to obtain films with sufficient thickness for optical measurements. The coated-films heat-treated once at $400^{\circ} \mathrm{C}$ were further heat-treated at temperatures ranging from $600^{\circ}$ to $1000^{\circ} \mathrm{C}$ for $15 \mathrm{~min}$ to $170 \mathrm{~h}$ to explore the effect of post heat treatment on the optical property.

Optical absorption spectra were measured from 200 to $800 \mathrm{~nm}$ at room temperature. By assuming that the microcrystals are spherical and the size distribution is not so diffuse, average crystal radius of Au microcrystals was calculated from the spectra according to Eq. (1).7)

$$
r=v_{\mathrm{F}} / \Delta \omega_{1 / 2}
$$

where $r$ is the crystal radius, $v_{\mathrm{F}}$ the Fermi velocity of electron and $1.39 \times 10^{8} \mathrm{~cm} / \mathrm{s}$ for $\mathrm{Au}$, and $\Delta \omega_{1 / 2}$ the full width at half maximum of the absorption peak.

Crystal radius and its distribution were also measured directly by using Hitachi $\mathrm{H}-800$ transmission electron microscope (TEM). For the TEM observation, Au-doped gel film was dip-coated on a platinum foil and heat-treated at $400^{\circ} \mathrm{C}$ for $15 \mathrm{~min}$, and then the glass film was scraped out from the foil.

Third order optical nonlinear susceptibility $\chi^{(3)}$ was measured for three $\mathrm{Au} / \mathrm{Si}=0.01$ samples with different thermal history by degenerate four-wave mixing (DFWM) method at $532 \mathrm{~nm}$ using a Qswitched Nd: YAG laser. The duration time of the laser pulse was about $6 \mathrm{~ns}$ in FWHM (full width at half maximum). The $\chi^{(3)}$ of the sample was calculated by Eq. (2) with the comparison of $\chi^{(3)} / \mathrm{C}$ of the sample with that of the standard,

$$
\left|\chi^{(3)}\right|=C \cdot \frac{n^{2}}{L} \cdot \frac{R^{1 / 2}}{I_{\mathrm{f}} I_{\mathrm{b}}} \cdot \frac{\ln (1 / T)}{T^{1 / 2}(1-T)}
$$

where $n, L, T$, and $R$ stand for the refractive index, thickness of the film, transmittance and the phase conjugate reflectivity of the sample, $I_{\mathrm{f}}$ and $I_{\mathrm{b}}$ are the forward and backward pump beam intensity, and $C=\lambda c / 24 \lambda^{3}$ is a constant independent from sample where $\lambda$ and $c$ are wavelength and velocity of light. $\mathrm{CS}_{2}$ was used as a standard sample and its $\chi^{(3)}$ was taken as $1.7 \times 10^{-12}$ esu. Refractive index of the sample was assumed to be equal to that of $\mathrm{SiO}_{2}$ glass, which is 1.461 at $532 \mathrm{~nm}$, since the concentration of $\mathrm{Au}$ is very low. Details of the configuration of the DFWM measurement system and the method of $\chi^{(3)}$ calculation have been described elsewhere. ${ }^{16)}$

\section{Results}

Figure 1 shows the absorption spectra of golddoped silica glass films with $\mathrm{Au} / \mathrm{Si}=0.01$ which were heat-treated at different temperatures for 15 min. Heating above $300^{\circ} \mathrm{C}$ induced the evolution of a peak of Au microcrystals around $545 \mathrm{~nm}$ in the spectrum, with the simultaneous dissipation of an absorption peak of $\mathrm{AuCl}_{4}{ }^{-}$anions around $310 \mathrm{~nm}$. This indicates that the decomposition of $\mathrm{AuCi}_{4}{ }^{-}$anions and the formation of Au metal microcrystals occurred in the temperature range from $200^{\circ}$ to $300^{\circ} \mathrm{C}$. This caused the color change of the dip-coated film from colorless to purple. Except for the peak height, there is no obvious difference in absorption spectrum among the samples heat-treated from $300^{\circ}$ to $600^{\circ} \mathrm{C}$. The shape of these spectra was not affected by heating duration.

Figure 2 shows the TEM photograph of an Audoped glass heat-treated at $400^{\circ} \mathrm{C}$. Two kinds of particles with different sizes were observed. One has average radius less than $10 \AA$ and the other has radius more than $20 \AA$. Both of the particles should be metallic $\mathrm{Au}$, because these particles were not seen in pure silica glass prepared by similar method, and because the temperature of heat treatment was much higher than the decomposition temperature of

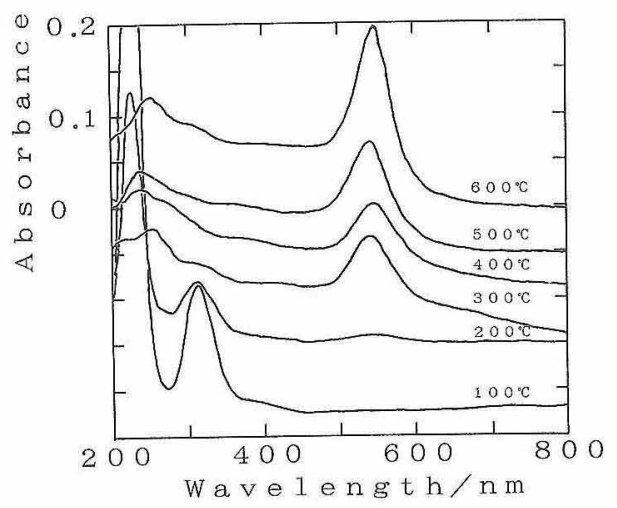

Fig. 1. Absorption spectra of five-times coated Au-doped glass films with the $\mathrm{Au} / \mathrm{Si}$ atomic ratio of 0.01 heat-treated at different temperatures ranging from $100^{\circ}$ to $600^{\circ} \mathrm{C}$. A silica glass was used as a reference sample.

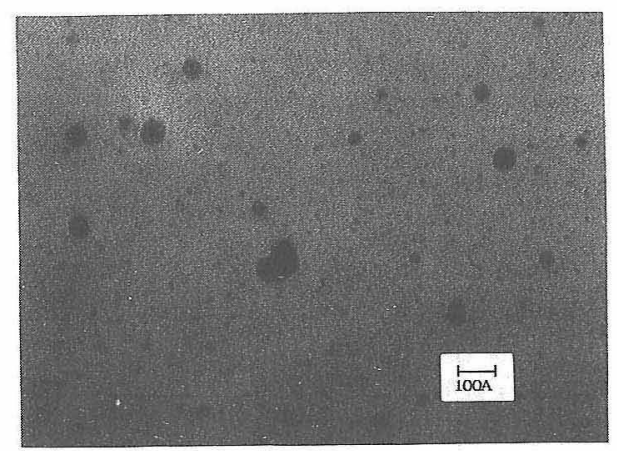

Fig. 2. TEM photograph of Au-doped glass with the $\mathrm{Au} / \mathrm{Si}$ atomic ratio of 0.01 heat-treated at $400^{\circ} \mathrm{C}$. 


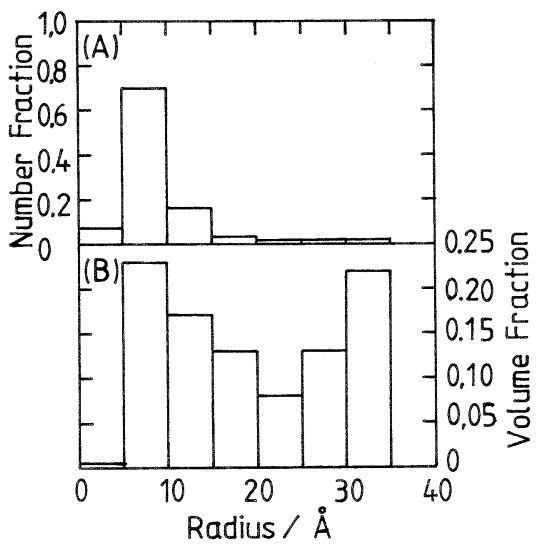

Fig. 3. Number (A) and volume (B) distributions of the $\mathrm{Au}$ microcrystal in the glass shown in Fig. 2.

$\mathrm{NaAuCl}_{4}$ to $\mathrm{Au}$. The number and volume distributions of the particles are shown in Figs. 3(A) and (B), respectively. More than 300 particles were accounted for obtaining the distribution. Although there is only one peak around $7 \AA$ in the number distribution of particle radius, two peaks, around $7 \AA$ and around $30 \AA$, are seen in the volume distribution of the radius. As the optical absorption coefficient is related to the volume fraction of particles, ${ }^{2)}$ volume distribution of the particles is important to understand the optical property of the sample.

Post heat treatment at $1000^{\circ} \mathrm{C}$ changed the absorption spectra of the Au-doped glass, and changed the color from purple to wine red. Figure 4 shows the absorption spectra of $\mathrm{Au} / \mathrm{Si}=0.01$ samples once heated at $400^{\circ} \mathrm{C}$ and then heat-treated at $1000^{\circ} \mathrm{C}$ for different durations up to $170 \mathrm{~h}$. This post heat treatment shifted the absorption peak to the short wavelength side and increased the peak width in a short time less than $1 \mathrm{~h}$. Further heating did not change the peak position but slowly made the peak width narrower, which may be caused by the increase in crystal radius. ${ }^{7)}$ The changes in position and FWHM of the peak as a function of heat treatment time is shown in Fig. 5. Apparent mean crystal radius calculated from FWHM using Eq. (1) is $40 \AA$ for $\mathrm{FWHM}=55$ $\mathrm{nm}, 34 \AA$ for $59 \mathrm{~nm}$, and $39 \AA$ for $52 \mathrm{~nm}$. As shown in

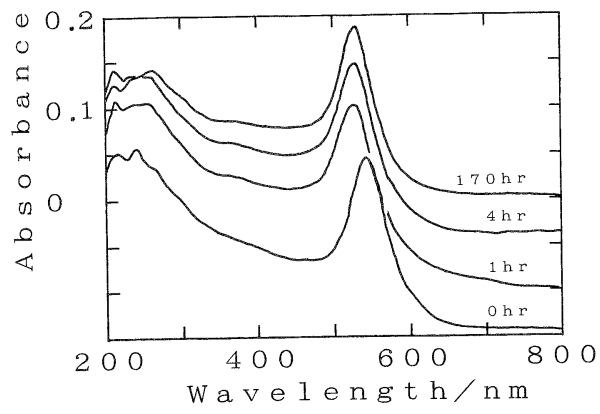

Fig. 4. Absorption spectra of ten-times coated Au-doped glass films with the $\mathrm{Au} / \mathrm{Si}$ ratio of 0.01 once heat-treated at $400^{\circ} \mathrm{C}$ and subsequently post heat-treated at $1000^{\circ} \mathrm{C}$ for 1 to $170 \mathrm{~h}$.

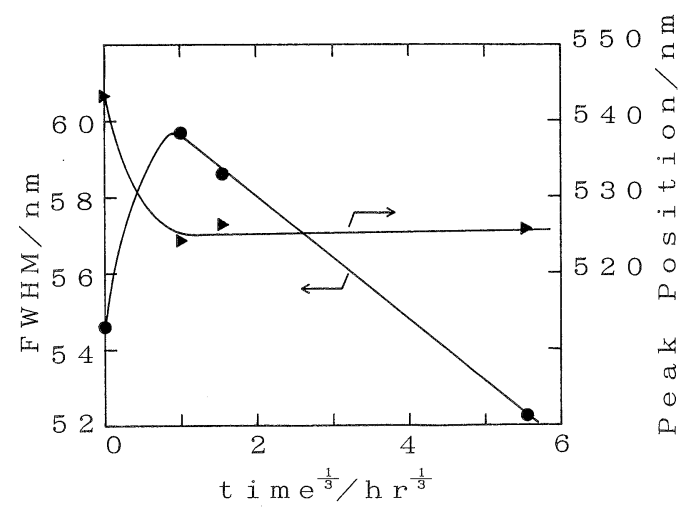

Fig. 5. Post heat treatment induced changes in absorption peak position and peak width of $400^{\circ} \mathrm{C}$-heated $\mathrm{Au}$-doped glass with the $\mathrm{Au} / \mathrm{Si}$ ratio of 0.01 as a function of heat treatment time at $1000^{\circ} \mathrm{C}$.

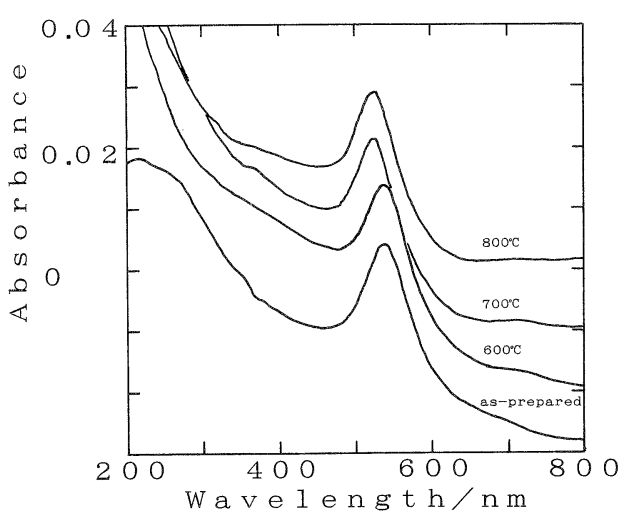

Fig. 6. Absorption spectra of Au-doped glass films with the $\mathrm{Au} /$ Si ratio of 0.01 once heat-treated at $400^{\circ} \mathrm{C}$ and subsequently post heat-treated at different temperatures ranging from $600^{\circ}$ to $800^{\circ} \mathrm{C}$ for $1 \mathrm{~h}$.

Fig. 6, similar changes in absorption spectrum were also observed after post heat treatment above $700^{\circ} \mathrm{C}$, but not observed at $600^{\circ} \mathrm{C}$.

Third order nonlinear susceptibility determined by DFWM method was listed in Table 1 for $\mathrm{Au} /$ $\mathrm{Si}=0.01$ samples with different thermal history. $\mathrm{Ab}-$ sorption coefficient at $450 \mathrm{~nm}$, which is a linear function of the total amount of Au microcrystals as revealed for crystals with the radius larger than $5 \AA,{ }^{17)}$ is also listed in the table. Third order nonlinear suscep-

Table 1. Optical nonlinearity of sol-gel derived Au microcrystaldoped silica glass measured by DFWM method at $532 \mathrm{~nm}$.

\begin{tabular}{lccc}
\hline $\begin{array}{l}\text { Preparation } \\
\text { Condition }\end{array}$ & $\begin{array}{l}\text { Absorption Peak } \\
\text { Position (nm) }\end{array}$ & $\begin{array}{c}\text { Abs. Coeff. at } \\
\text { 450nm }\left(\mu \mathrm{m}^{-1}\right)\end{array}$ & $\begin{array}{c}\chi^{(3)} \\
(\mathrm{esu})\end{array}$ \\
\hline & 547 & 0.32 & $7.2 \times 10^{-9}$ \\
$400^{\circ} \mathrm{C}$ & 528 & 0.30 & $3.4 \times 10^{-9}$ \\
$400^{\circ} \mathrm{C} \quad$ and & & & \\
$1000^{\circ} \mathrm{C}, 1 \mathrm{hr}$ & 544 & 0.30 & $7.7 \times 10^{-9}$ \\
$600^{\circ} \mathrm{C}$ & & & \\
\hline
\end{tabular}




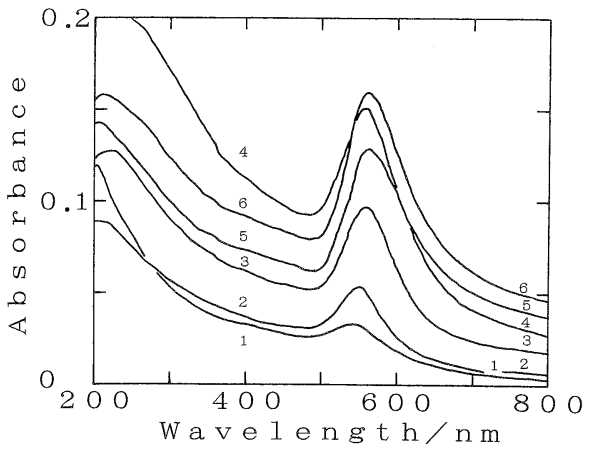

Fig. 7. Absorption spectra of two-times coated Au-doped glass films with different $\mathrm{Au} / \mathrm{Si}$ atomic ratios which was heat-treated at $400^{\circ} \mathrm{C}$. After the two-times coating and heating, the samples were wiped with tissue paper before the absorption measurement. The numerals in the figure are the $\mathrm{Au} / \mathrm{Si}$ atomic ratios in the coating solutions multiplied by 100 .

tibility $\chi^{(3)}$ of the sample heat-treated at $400^{\circ} \mathrm{C}$ was $7.2 \times 10^{-9} \mathrm{esu}$. The $\chi^{(3)}$ of the sample heat-treated at $600^{\circ} \mathrm{C}$ was similar to that prepared at $400^{\circ} \mathrm{C}$, being consistent with the similarity in absorption spectra of these two samples. On the other hand, the sample once heated at $400^{\circ} \mathrm{C}$ and then post heat-treated at $1000^{\circ} \mathrm{C}$ showed lower $\chi^{(3)}$ value, although the peak position in absorption spectrum was very close to the wavelength of pump and probe light in this sample.

Figure 7 shows the absorption spectra of samples with different $\mathrm{Au}$ contents. Au microcrystal-doped glasses with $\mathrm{Au} / \mathrm{Si}$ ratio up to 0.04 were successfully prepared. Absorption spectra of the samples with $\mathrm{Au} / \mathrm{Si}$ atomic ratio from 0.01 to 0.04 represent similar shape around the absorption peak with the change in intensity. The color of these films was purple in both transmission and reflection. When $\mathrm{Au} / \mathrm{Si}$ ratio was increased to 0.05 or more, the obtained film became rough surfaced and was seen by naked eyes as mat gold-colored in reflection. In this case, very small gold-colored powders were formed on the surface and they were able to be wiped out easily. Similar behavior was found by Kozuka and Sakka15) using $\mathrm{HAuCl}_{4} \cdot 4 \mathrm{H}_{2} \mathrm{O}$ as a starting material. Absorption spectra shown in Fig. 7 are those after wiped, and the peak intensity of these samples was similar to that of $\mathrm{Au} / \mathrm{Si}=0.04$.

\section{Discussion}

Decomposition of $\mathrm{AuCl}_{4}{ }^{-}$anions and the formation of Au microcrystals occurred between $200^{\circ}$ and $300^{\circ} \mathrm{C}$ in the film. This temperature is somewhat higher than the decomposition temperature of pure $\mathrm{NaAuCl}_{4} \cdot 2 \mathrm{H}_{2} \mathrm{O}$ to form metallic $\mathrm{Au}$ in the air. As the $\mathrm{AuCl}_{4}{ }^{-}$anion is surrounded by silica network in the gel film and thus the equilibrium of the decomposition reaction, $\mathrm{AuCl}_{4}{ }^{-}=\mathrm{Au}+3 / 2 \mathrm{Cl}_{2}+\mathrm{Cl}^{-}$, may shift to the left hand side because of the accumulation of $\mathrm{Cl}_{2}$ in the film due to low diffusion of $\mathrm{Cl}_{2}$ through the gel network.

The Au atoms produced by the decomposition of
$\mathrm{AuCl}_{4}{ }^{-}$should tend to aggregate to form microcrystal. The distribution of crystal radius shows that the fraction of microcrystal with the radius of about $7 \AA$ is very high. When we assume that the structure of the microcrystal is the same as that of bulk crystal, that is fcc, and that the atomic radius of Au in the microcrystal is nearly the same as that in the bulk, then the crystal radius of $7 \AA$ corresponds to the cluster of $\mathrm{Au}_{85}$ (crystal radius of $6 \AA$ corresponds to $\mathrm{Au}_{54}$ and that of $8 \AA$ corresponds to $A u_{127}$ ). It is known that a stable $\mathrm{Au}_{55}$ cluster with ligands at the surface can be synthesized by chemical process, ${ }^{18)}$ and its structure is based on the fcc lattice like in the bulk crystal or constructed by $8\left(=2^{3}\right)$ unit cells without cornered eight atoms. ${ }^{19)}$ Considering that the crystal radius determined by TEM has a tendency toward overestimating because of the incompleteness of focussing, therefore, the microcrystals with the radius of about $7 \AA$ in the present $\mathrm{SiO}_{2}$ glass film may be above mentioned $\mathrm{Au}_{55}$ cluster, or related to it and written as $\mathrm{Au}_{55+\alpha^{\prime}}$, which may be stable as a form of bare cluster, with being coordinated by silica network, like that of a chemically synthesized ligand-covered cluster. Though $\mathrm{Au}_{13}$ cluster with ligands is also known to be stable as well as $\mathrm{Au}_{55}$ cluster, ${ }^{20)}$ whether clusters of this type exist in this glass film or not cannot be determined because the cluster size is smaller than the TEM resolution limit.

Clusters having radius larger than $10 \AA$ may be formed by aggregation or by growth of the $7 \AA$ clusters. As the evolution of $545 \mathrm{~nm}$ peak and dissipation of $310 \mathrm{~nm}$ peak took place in a short time less than $15 \mathrm{~min}$ on heating the gel film at a temperature less than $600^{\circ} \mathrm{C}$ and longer heat treatment has no more effect, it is considered that the formation and growth of $\mathrm{Au}$ microcrystals occur at the gel state or during the gel to glass conversion process, and does not occur once a rigid and dense glass network is formed.

The volume fraction profile of crystal has two peaks around $30 \AA$ and around $7 \AA$. The former fairly corresponds to the radius calculated from the FWHM of the optical absorption peak. Although the absorption by $7 \AA$-radius microcrystals occur at similar wavelength to $\mathrm{Au}_{55}$ cluster which shows the absorption around $520 \mathrm{~nm},{ }^{18}$ ) the very low absorption coefficient and the extremely broad peak width makes the peak undistinguishable when it is overlapped with a strong and sharp peak caused by $30 \AA$ centered microcrystals. Thus, the crystal radius obtained from FWHM represents the average crystal radius of microcrystals involving the larger radius group in the volume distribution histogram. Eventually, the difference of average crystal radius calculated from FWHM and that observed by TEM may be originated from the too simple assumptions to derive Eq. (1).

Third order nonlinear optical susceptibility $\chi^{(3)}$ of $400^{\circ} \mathrm{C}$ heat-treated Au-doped glass was $7.2 \times 10^{-9}$ 
esu, and $7.7 \times 10^{-9}$ esu for $600^{\circ} \mathrm{C}$ heat-treated one. The nonlinear susceptibility of $\mathrm{Au}$ microcrystals themselves in the film, $\chi_{\mathrm{m}}{ }^{(3)}$, can be calculated by using the following relations ${ }^{2)}$

$$
\begin{aligned}
& f_{1}(\omega)=\frac{3 \varepsilon_{\mathrm{d}}}{\varepsilon_{\mathrm{m}}(\omega)+2 \varepsilon_{\mathrm{d}}} \\
& \chi^{(3)}=p f_{1}^{2}\left|f_{1}\right|^{2} \chi_{\mathrm{m}}{ }^{(3)}
\end{aligned}
$$

where $\varepsilon_{\mathrm{m}}(\omega)=\varepsilon_{\mathrm{m}}{ }^{\prime}+\varepsilon_{\mathrm{m}}{ }^{\prime \prime}$ is the frequency dependent complex dielectric constant of Au particle, $\varepsilon_{\mathrm{d}}$ is the real part of that of the glass matrix (imaginary part is negligible at this wavelength), and $p$ is the volume fraction of Au particles. By using the complex refractive index of bulk gold ${ }^{21)}$ for calculating $\varepsilon_{\mathrm{m}}(\omega)$ and putting $\varepsilon_{\mathrm{d}}=1.461^{2}$, which is the square of the refractive index of silica glass at $532 \mathrm{~nm}$, the $\chi_{\mathrm{m}}{ }^{(3)}$ in theses two glasses was estimated as $1.0 \times 10^{-7}$ esu. This value is similar to that in a glass prepared by ion implantation, that is $8 \times 10^{-8} \mathrm{esu}^{11)}$ and is also similar to the value in the sputter-derived glass calculated from the $\chi^{(3)}$ data in Ref.13). These $\chi_{m}{ }^{(3)}$ values are about two times larger than that observed in Audoped glasses prepared by melting and subsequent heat treatment. ${ }^{2)}$

Nonlinear susceptibility of the glass film rapidly decreased to about half when the sample was post heat-treated at $1000^{\circ} \mathrm{C}$. This heat treatment also caused the shift of the absorption peak from $545 \mathrm{~nm}$ to $528 \mathrm{~nm}$ and the narrowing of the width of this peak. So the changes in nonlinear susceptibility and in absorption spectrum should be correlated. The direction of change in optical absorption with time is opposite to that expected to occur by crystal growth, then other phenomena must be considered. The major change in the absorption spectrum took place in a short time during post heat treatment, and after this the change became very slow and even opposite to the initial one, suggesting that the initial rapid change is a relaxation phenomenon of microstructure. Since the formation of Au microcrystals in the present work is very rapid, there may be a possibility to form microcrystals which have thermodynamically unstable morphology such as nonspherical clusters, and these may be reformed to thermodynamically stable microstructure by heat treatment at temperatures sufficiently high for atomic diffusion. Thus, the observed results can be explained in terms of the narrower absorption peak and higher nonlinear susceptibility of the unstable cluster above mentioned.

Optical susceptibility of the Au microcrystals themselves in the films, $\chi_{\mathrm{m}}{ }^{(3)}$, after the heat treatment at $1000^{\circ} \mathrm{C}$ is estimated as $6 \times 10^{-8} \mathrm{esu}$. This value is equal to that in the glasses prepared by melting and subsequent heat treatment where the microcrystals with thermodynamically stable structure may have been formed. As both ion implantation and sputtering are high energy processes so that the obtained glasses are highly supersaturated by $\mathrm{Au}$ atom, the microcrystals precipitated by subsequent heat treatment may be different from the stable structure one and have high $\chi_{\mathrm{m}}{ }^{(3)}$ values. Furthermore, the Au-supersaturated nature of the glass network may prevent the relaxation of microstructure to the low $\chi_{\mathrm{m}}{ }^{(3)}$ form. Change in absorption peak width by long time heat treatment may be due to the crystal growth.

The atomic ratio of $\mathrm{Au} / \mathrm{Si}$ can be increased to 0.04 from 0.01 . Further addition of $\mathrm{NaAuCl}_{4} \cdot 2 \mathrm{H}_{2} \mathrm{O}$ to the coating solution was not effective to increase the $\mathrm{Au}$ content in the film. The absorption peak height of $\mathrm{Au} / \mathrm{Si}=0.05$ and 0.06 glasses measured after wiping the surfaces were similar to that of $\mathrm{Au} / \mathrm{Si}=0.04$ glass, implying that the excess $\mathrm{Au}$ is discharged from the glass film. The absorption spectrum of the glass with $\mathrm{Au} / \mathrm{Si}=0.04$ is similar to that of $\mathrm{Au} /$ $\mathrm{Si}=0.01$ glass except for the amplitude, then, it is considered that the microstructure and the size of $\mathrm{Au}$ microcrystals in these glasses are the same. So, nonlinear susceptibility of about $3 \times 10^{-8} \mathrm{esu}$ would be expected by multiplying the $\chi^{(3)}$ of $\mathrm{Au} / \mathrm{Si}=0.01$ glass by the increment of the content of $\mathrm{Au}$, i.e. four.

\section{Conclusion}

Au microcrystal-doped glass films were prepared by sol-gel method with dip-coating using $\mathrm{NaAuCl}_{4}$. $2 \mathrm{H}_{2} \mathrm{O}$ and TEOS as starting materials. Glass films with the $\mathrm{Au} / \mathrm{Si}$ atomic ratio of 0.01 were successfully prepared by heating the gel films at a temperature ranging from $300^{\circ}$ to $600^{\circ} \mathrm{C}$. These films showed the nonlinear susceptibility $\chi^{(3)}$ of $7.7 \times 10^{-9}$ esu. Microcrystals with the radius of about $7 \AA$ and of about $30 \AA$ coexist in the glass film. Subsequent heat treatment of these glass films at $1000^{\circ} \mathrm{C}$ shifted the absorption peak from $545 \mathrm{~nm}$ to $528 \mathrm{~nm}$, made the width of this peak narrower, and decreased $\chi^{(3)}$ of the film by a factor of two. The nonlinear susceptibility of Au microcrystal itself, $\chi_{\mathrm{m}}{ }^{(3)}$, in the as-prepared film was $1.0 \times 10^{-7}$ esu, which is nearly the same as that of glasses prepared by ion implantation or sputtering. The $\chi_{\mathrm{m}}{ }^{(3)}$ of the $1000^{\circ} \mathrm{C}$-heat-treated film was about the half of this value and is the same as that observed in Au-doped glasses prepared by melting and subsequent heat treatment. The atomic ratio of $\mathrm{Au} /$ Si can be increased to 0.04 , where $\chi^{(3)}$ of about $3 \times$ $10^{-8}$ is expected.

Acknowledgment This work was partially supported by the Grant-in-Aid for Scientific Research from the Ministry of Education, Science and Culture of Japan.

\section{References}

1) D. Ricard, Ph. Roussignol and Chr. Flytzanis, Opt. Lett., 10, 511-13 (1985).

2) F. Hache, D. Ricard, C. Flytzanis and K. Kreibig, Appl. Phys., A47, 347-57 (1988).

3) T. Dutton, B. VanWonterghem, S. Saltiel, N. V. Chestnoy, P. M. Rentzepis, T. P. Shen and D. Rogovin, J. Phys. Chem., 94, 1100-05 (1990).

4) E. J.Heolweil and R. M. Hochestrasser, J. Chem. Phys., 82, 
4762-70 (1985).

5) M. J. Bloemer, J. W. Haus and P. R. Ashley, J. Opt. Soc. Am., B7, 790-95 (1990).

6) R. H. Ritchie, Surface Science, 34, 1-19 (1973).

7) G. W. Arnold, J. Appl. Phys., 46, 4466-73 (1975).

8) U. Kreibig, J. de Physique Colloque, C2, 97-103 (1977).

9) A. W. Olsen and Z. H. Kafafi, J. Am. Chem. Soc., 113, 775860 (1991).

10) Y. Ng Cheong Chan and R. R. Schrock, Chem. Mater., 4, 24-27 (1992).

11) K. Fukumi, A. Chyayahara, K. Kadono, T. Sakaguchi, Y. Horino, M. Miya, J. Hayakawa and M. Satou, Jpn. J. Appl. Phys., 30, L742-44 (1991).

12) idem, "Science and Technology of New Glasses, Proceedings of the International Conference on Science and Technology of New Glasses", Ed. by S. Sakka and N. Soga, The Ceram. Soc. Japan (1991) pp. 353-58.

13) H. Wakabayashi, H. Yamanaka, K. Kadono, T. Sakaguchi and M. Miya, ibid., pp. 412-17.

14) J. Matsuoka, R. Mizutani, H. Nasu and K. Kamiya, J. Cer- am. Soc. Japan, 100, 599-601 (1992).

15) H. Kozuka and S. Sakka, presented at the Annual Meeting of the Ceramic Society of Japan, May, 1992, and the manuscript submitted to Chem. Mater.

16) T. Sakaguchi, M. Miya and T. Fukumi, Report on Topical Meeting of the Laser Society of Japan, No. RTM-91-17 (1991) pp. 39-44 (in Japanese).

17) R. H. Doremus, J. Chem. Phys., 40, 2389-96 (1964).

18) G. Schmid, R. Pfeil, R. Boese, F. Bandermann, S. Meyer, G. H. M. Calis and J. A. M. van der Verden, Chem. Ber., 144, 3634-42 (1981).

19) M. A. Marcus, M. P. Andrews, J. Zegenhagen, A. S. Bommannavar and P. Montano, Phys. Rev., B42, 3312-16 (1990).

20) C. E. Briant, B. R. C. Theobald, J. W. White, L. K. Bell, D. M. P. Mingos and A. J. Welch, J. Chem. Soc., Chem. Commun., 1981, 201-02.

21) D. W. Lynch and W. R. Hunter, "Handbook of Optical Constants of Solids", Ed. by E. D. Palik, Academic Press, Orland (1985) pp. 286-95. 